\title{
PV Module Parameters Estimation Using Newton Raphson
}

\author{
Ranjith Dharmarajan $^{1 *}$, Rajeswari Ramachandran ${ }^{2}$ \\ ${ }^{I} P G$ Scholar, Department of Electrical Engineering, Government College of Technology, Coimbatore, TN, India \\ ${ }^{2}$ Associated Professor, Department of Electrical Engineering Government College of Tech, Coimbatore, TN, India
}

*Corresponding author E-Mail ID: ranjithgct17@gmail.com, Mobile: +91 9790978785

DOI: https://doi.org/10.34256/irjmt19219

\begin{abstract}
The estimation of solar photovoltaic (PV) system with help of electrical model parameters, such as photon generated current, the diode saturation current, series resistance, shunt resistance, and diode ideality factor, are desirable to predict the real performance characteristics of solar PV under varying environmental conditions. Finally, performance indices, such as PV characteristics curve are estimated for the various solar PV panels, using Newton Raphson (NR) to reveal the effectiveness of the proposed method. Also, validation with 'experimental data has been considered. Finally, through the comparative analysis of the results, it is revealed that the proposed method offers solar PV characteristics closer to the real characteristics.
\end{abstract}

\section{Keywords: Newton Raphson (NR), Photovoltaic (PV).}

\section{INTRODUCTION}

Solar panels harness the sun energy in the form of light and convert the energy into electricity. Although the average consumer might associate solar panels with residential rooftop assemblies, solar panels are available for a wide range of applications, including powering individual gadgets, electronic devices and vehicle batteries.

The reserves of fossil fuels are rapidly decreasing at present due to the increased use of thermal power plants and air pollution associated with the combustion of fossil fuels is increasing. Hence, in the present scenario, there is an urgent need to speed up the research and development of renewable energy technology, especially solar energy, to meet the world energy demand.

The goal of this dissertation is to develop and apply an integrated assessment framework, for one of the sustainable electricity options, solar photovoltaic (PV) technology. In this dissertation different types of photovoltaic modules are considered that are widely manufactured in the market at present, and the future implications of using PV technology in the electricity sector is evaluated.

The word 'Sustainable' in this context implies energy, environmental and economic sustainability. Higher output energy generated by the PV panels during their lifetime when compared to the input energy for manufacturing and end of life management constitutes energy sustainability. Generating cleaner (lower criteria pollutants and greenhouse gas emissions 

released) electricity when compared to the grid electricity sources constitutes environmental sustainability.

PV electricity mitigates emissions from thermal power plants to the grid. Inclusion of such monetary benefits from mitigation into the evaluation of the economic performance, PV technology encourage economic sustainability.

\section{ANALSIS OF SINGLE DIODE PV MODULE}

A single diode model of the solar PV module is have the unknown parameters from figure 1 , namely $I_{\mathrm{g}}, \mathrm{I}_{\mathrm{sat}}, \mathrm{A}, \mathrm{R}_{\mathrm{se}}$, and $\mathrm{R}_{\mathrm{sh}}$. By taking the datasheet information provided by the manufacturer of the PV module at standard test conditions (STCs), the PV module's parameters are estimated.

\subsection{Single Diode Solar PV Module}

A single diode model of the PV module is shown in Figure 1. Using Kirchhoff's current law, the I $-\mathrm{V}$ relationship of the PV module can be written as follows [10, 11]. By using the PV module parameters obtained at STCs, the values of the five parameters and the MPP of the PV module can be estimated at any temperature and irradiance condition.

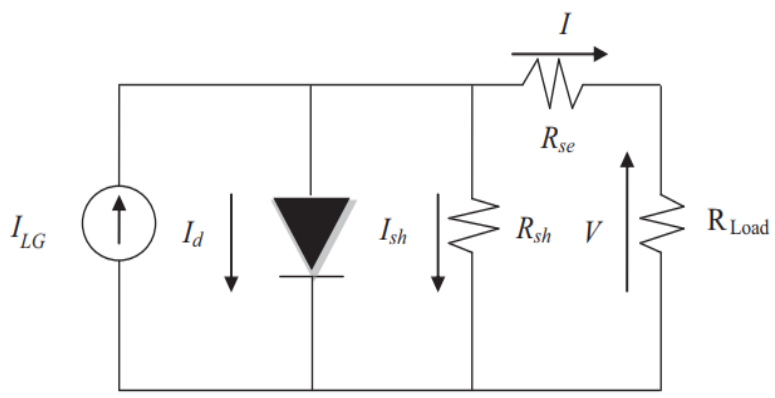

Fig 1. Equivalent circuit of PV module

$$
I=I_{l g}-I_{s a t}\left[e\left(V+\frac{I_{s e}}{N_{s} V_{t}}\right)-1\right]-\frac{V+I_{s e}}{R_{s h}}
$$

Where,

$\mathrm{I}_{\mathrm{lg}}$ - Light generated current in amps

$\mathrm{N}_{\mathrm{S}}$-Number of solar cells connected in series

$\mathrm{I}_{\text {sat- }}$ Diode reverse saturation current in amps

$\mathrm{R}_{\mathrm{se}}$-Series resistance of solar module in ohms

$\mathrm{R}_{\mathrm{sh}}-$ Shunt resistance of solar module in ohms

The thermal voltage of diode, $\mathrm{V}_{\mathrm{t}}$, is expressed as,

$$
\mathrm{V}_{\mathrm{t}}=\mathrm{AkT}_{\mathrm{c}} / \mathrm{q}
$$


Where,

A- Diode ideality factor

$\mathrm{k}$-Boltzmann constant $\left(1.3806 * 10^{\wedge}-23 \mathrm{~J} / \mathrm{K}\right)$

$\mathrm{T}_{\mathrm{c}}$ - PV module temperature (STC) in $\mathrm{K}$

$\mathrm{q}$ - Electronic charge $\left(1.602 * 10^{\wedge}-19 \mathrm{C}\right)$

The important parameters to be noted from the manufacturer's datasheet are short circuit current $\left(\mathrm{I}_{\mathrm{sc}}\right)$, open circuit voltage $\left(\mathrm{V}_{\mathrm{oc}}\right)$, and maximum power point are $\left(\mathrm{V}_{\mathrm{mpp}} \& \mathrm{I}_{\mathrm{mpp}}\right)$. The values at STCs, for which the irradiance $\left(\mathrm{G}_{\text {stc }}\right)$ is $1000 \mathrm{~W} / \mathrm{m}^{2}$ and the cell temperature $\left(\mathrm{T}_{\text {stc }}\right)$ is $25 \circ \mathrm{C}$. The data sheet also provides temperature coefficients for short circuit current (ki), open circuit voltage $(\mathrm{kv})$, and maximum power (kp).

\subsubsection{Extraction of PV Module Parameters}

The five unknown parameters are to be estimate of the PV module from the nonlinear equation (1), five independent equations are required. The first three equations, (4), (7), and (9), are derived from Eq. (1) by applying short circuit, open circuit, and MPP conditions. The remaining two equations, (12) and (14), are derived by differentiating the values of power and current with respect to voltage.

\subsection{Short Circuit Condition (SCC)}

Under the short circuit condition,

$$
I_{s c}=I_{l g} I_{s a t}\left[e\left(\frac{I_{g c} R_{s h}}{N_{g} V_{t}}\right)-1\right]-\left(\frac{I_{g e} R_{g e}}{R_{s h}}\right)
$$

After some approximation, the light generated current $\left(\mathrm{I}_{\mathrm{lg}}\right)$ can be written as

$$
I_{l g}=\frac{I_{g c}\left(R_{g e}+R_{g h}\right)}{R_{g h}}
$$

\subsection{Open Circuit Condition (OCC)}

Under the open circuit condition,

$$
0=I_{\text {lg }}-I_{g a t} e\left(\frac{V_{o c}}{N_{g} V_{t}}\right)-\frac{v_{o c}}{R_{g h}}
$$

This equation is rearranged and the reverse saturation current is expressed as

$$
I_{\text {sat }}=\left(I_{l g}-\frac{V_{o c}}{R_{s h}}\right) e\left(-\frac{V_{o c}}{N_{s} V_{t}}\right)
$$

Substituting $\mathrm{I}_{\lg }$ from short circuit, the saturation current can be derived as,

$$
I_{s a t}=\left(\frac{I_{s e}\left(R_{s e}+R_{s h}\right)-V_{0 c}}{R_{s h}}\right) e\left(-\frac{V_{0 c}}{N_{s} V_{t}}\right)
$$




\subsection{Maximum Power Point (MPP) Condition}

The maximum power point calculation are as follows:

$$
I_{m p p}=I_{l g}-I_{\text {sat }}\left[e\left(\frac{V_{m p p}+I_{m p p} R_{s e}}{N_{g} V_{t}}\right)-1\right]-\frac{V_{m p p}+I_{m p p} R_{s e}}{R_{s h}}
$$

Inserting $I_{l g}$ and $I_{\text {sat }}$ into this equation, we get the equation as

$$
\begin{aligned}
I_{m p p}=\left(\frac{I_{s c}\left(R_{s e}+R_{s h}\right)-\left(V_{m p p}+I_{m p p} R_{s e}\right)}{R s h}\right) \\
-\left(\frac{I_{s c}\left(R_{s e}+R_{s h}\right)-V_{o c}}{R_{s h}}\right) e\left(\frac{V_{m p p}+I_{m p p} R_{s e}-V_{o c}}{N_{s} V_{t}}\right)
\end{aligned}
$$

\subsection{Calculation of Initial Values}

To select the initial value for $R_{s e}$ and $R_{s h}$, the following equations are considered. Because of high sensitivity, the numerical methods may fail to converge due to improper selection of the initial value of the PV module parameters.

$$
\begin{aligned}
& R_{s e} \text { initial }=\left(\frac{V_{o c}}{I_{s e}}\right)-\left(\frac{V_{m p p}}{I_{m p p}}\right) \\
& R_{s h} \text { initial }=V_{m p p} /\left(I_{s c}-I_{m p p}\right)
\end{aligned}
$$

The $V_{t}, R_{s e}$ and $R_{s h}$ are given by the equations,

$$
\begin{gathered}
V_{t}=\frac{V_{m p p}+I_{m p p} R_{s e}-V_{o c}}{\left(N_{s} \ln \left(\frac{I_{s c}\left(R_{s e}+R_{s h}\right)-V_{o c}}{\left(I_{s c}-I_{m p p}\right)\left(R_{s e}+R_{s h}\right)-V_{m p p}}\right)\right.} \\
R_{s e}=\frac{V_{o c}-V_{m p p}+N_{s} V_{t} s}{I_{m p p}}
\end{gathered}
$$

Where,

$$
\begin{aligned}
& S=\ln \left(\frac{\left(N_{s} V_{t}\left(I_{m p p}\left(R_{s e}+R_{s h}\right)-V_{m p p}\right)\right.}{I_{s c} V_{m p p}\left(R_{s e} R_{s h}\right)+I_{m p p} R_{s e}\left(V_{o c}-I_{s c} R_{s e}-I_{s c} R_{s h}\right)-V_{m p p} V_{o c}}\right)
\end{aligned}
$$

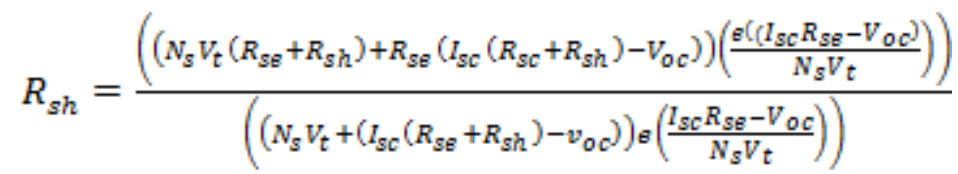


The PV module parameters $I_{l g}, I_{s a t}, A, R_{s e}$ and $R_{s h}$ can be obtained by open and short circuit test. First, these three equations are solved by newton Raphson method and the values of $\mathrm{V}_{\mathrm{t}}, R_{s e}, R_{s h}$ are obtained

The remaining parameters are obtained from short and open circuit test using the values of $V_{t}, R_{s e}, R_{s h}$.

\subsection{Effect of Varying Irradiance and Temperature}

The light generated current and short circuit current are directly proportional to irradiance and depends on temperature.

$$
\begin{aligned}
& I_{l_{g}(G)}=I_{l_{g}(s t c)} \times \frac{G}{G_{s t c}} \\
& I_{s c(G)}=I_{s c(s t c)} \times \frac{G}{G_{g t c}}
\end{aligned}
$$

Where,

$G_{\text {stc }}-$ Irradiance at STC $\left(\mathrm{w} / \mathrm{m}^{2}\right)$

$\mathrm{G}$ - Irradiance under given operating condition

The open circuit voltage equation can be described as the function of irradiance as given by and this equation is solved by Newton Raphson.

$$
V_{\text {oc }(G)}=N_{s} V_{t} \ln \left(\frac{I_{\lg (G)} R_{s h}-V_{o c}(G)}{I_{s a t} R_{s h}}\right)
$$

The short circuit current and open circuit voltage can be evaluated for the given operating temperature as given by

$$
\begin{array}{r}
I_{s c(T)}=I_{s c(s t c)}+k_{i}\left(T_{c}-T_{s t c}\right) \\
V_{o c(\tau)}=V_{o c(s t c)}+K_{v}\left(T_{c}-T_{s t c}\right)
\end{array}
$$

Where,

$$
T_{\text {sto }} \text { - Cell temperature at STC, K. }
$$
by,

The light generated current can be determined as a function of temperature and is given

$$
I_{\lg (T)}=I_{s c(T)}\left(R_{s e}+R_{s h}\right) /\left(R_{s h}\right)
$$


The short circuit current, open circuit voltage and light generated current can be estimated at any temperature and irradiance using the following three equations.

$$
\begin{aligned}
& I_{\mathrm{lg}(G T)}=\left(I_{l_{g}(s t c)}+k_{i}\left(T_{c}-T_{s t c}\right)\right)\left(\frac{G}{G_{s t c}}\right) \\
& I_{s c(G T)}=\left(I_{s c(s t c)}+k_{i}\left(T_{c}-T_{s t c}\right)\right)\left(\frac{G}{G_{s t c}}\right) \\
& V_{o c(G T)}=V_{o c(G)}+K_{v}\left(T_{c}-T_{s t c}\right)
\end{aligned}
$$

The thermal voltage $V_{t}$ is directly proportional to PV panel cell temperature and is given by,

$$
V_{t(T)}=V_{t(s t c)}\left(\frac{T}{T_{s t c}}\right)
$$

The diode reverse saturation current, which is a function of irradiance and temperature can be calculated from the equation,

$$
I_{\text {sat }(G T)}=\frac{I_{S e(G)}\left(R_{g e}+R_{S h}\right)-V_{o c(G T)}}{R_{s h}} e\left(-\frac{V_{o c(G T)}}{N_{S} V_{t(T)}}\right)
$$

\subsection{Estimation of Maximum Power Point}

The proper initial values of $V_{m p p}$ and $I_{m p p}$ should be chosen to estimate the accurate MPP by using the well-known values of $V_{o c}$ amd $I_{s c}$ under given operating conditions. Under varying irradiance and temperature, $V_{t(G T)}, R_{s e(G T)}$ and $R_{s h(G T)}$ are obtained by using the estimated parameters of the PV module such as $I_{l g}, I_{s a t}, A_{,} R_{s e}$, and $R_{s h}$ at STC's. conditions.

In general, the PV module parameters change considerably due to various environmental

$$
R_{s e(G T)}=R_{s e(s t c)}\left(\frac{I_{\operatorname{Ig}(G T)}}{\left.I_{\operatorname{Ig}(s t c)}\right)}\right.
$$

The value of shunt resistance is considered a constant in [10] but the value of shunt resistance of the PV module is indirectly proportional to the short circuit current under varying operating conditions in this paper, anew equation is introduced for the shunt resistance variation with respect to temperature and irradiance and is expressed as

$$
R_{s h(G T)}=R_{s h(s t c)}\left(\frac{I_{s e(s t c)}}{I_{s e(G T)}}\right)
$$

In order to find MPP, The maximum voltage is found as a function of temperature and irradiance and is given by,

$$
V_{m p p}=V_{o c(G T)}-I_{m p p} R_{s e(G T)}+N_{s} V_{t(G T)} U
$$


Where,

$$
U=\ln \left(\frac{\left(\left(I_{s c(G T)}-I_{m p p}\right)\left(R_{s e(G T)}+R_{s h(G T)}\right)-V_{m p p}\right)}{I_{s e(G T)}\left(R_{s e(G T)}+R_{s h(G T)}-V_{o \sigma(G T)}\right)}\right)
$$

The maximum current serves as a function of temperature and irradiance and is given by,

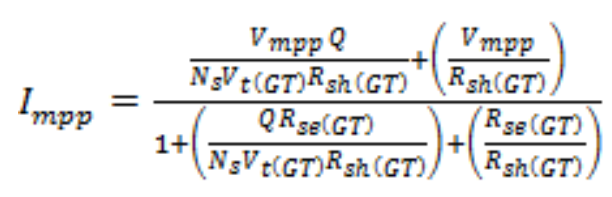

Where,

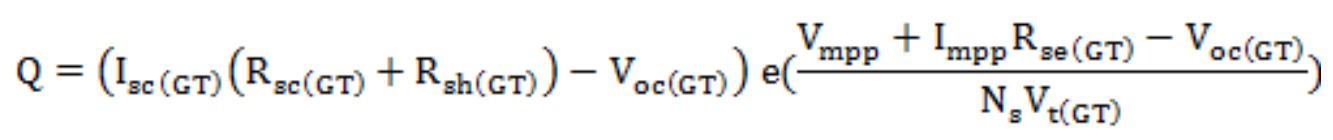

These three equations can be solved using the Newton Raphson method and Generalised Hopfield Neural Network method. In these two method the error value is taken as the $1 \times 10 \mathrm{e}-10$. These are all the mathematical modelling of the $80 \mathrm{~W}$ PV module that can be used for extracting the five parameters and finding the maximum power point of the prescribed PV module.

\section{ESTIMATION OF PV MODULE PARAMETERS}

The parameters of PV module are namely $I_{\mathrm{lg}}, \mathrm{I}_{\mathrm{sat}}, \mathrm{A}, \mathrm{R}_{\mathrm{se}}$, and $\mathrm{R}_{\mathrm{sh}}$. By taking the datasheet information Table 1, provided by the manufacturer of the PV module at standard test conditions (STCs), the PV module's parameters are estimated. By using the PV module parameters obtained at STCs, the values of the five parameters and the MPP of the PV module can be estimated at any temperature and irradiance condition.

\subsection{PV Module Parameters Estimation Under STCs Using Newton-Raphson Method}

In this section about the solution of a set of nonlinear equations through Newton-Raphson method. Let us consider that a set of $n$ nonlinear equations of a total number of $n$ variables $x_{1}, x_{2}$, $\ldots, x_{n}$. Let these equations be given by

$$
\begin{gathered}
f_{1}\left(x_{1}, \cdots, x_{n}\right)=\eta_{1} \\
f_{2}\left(x_{1}, \cdots, x_{n}\right)=\eta_{2} \\
\vdots \\
f_{n}\left(x_{1}, \cdots, x_{n}\right)=\eta_{n}
\end{gathered}
$$


Where $f_{1}, \ldots, f_{n}$ are functions of the variables $x_{1}, x_{2}, \ldots, x_{n}$. Then another set of functions $g_{1}$, $\ldots, g_{n}$ as given below

$$
\begin{gathered}
g_{1}\left(x_{1}, \cdots, x_{n}\right)=f_{1}\left(x_{1}, \cdots, x_{n}\right)-\eta_{1}=0 \\
g_{2}\left(x_{1}, \cdots, x_{n}\right)=f_{2}\left(x_{1}, \cdots, x_{n}\right)-\eta_{2}=0 \\
\vdots \\
g_{n}\left(x_{1}, \cdots, x_{n}\right)=f_{n}\left(x_{1}, \cdots, x_{n}\right)-\eta_{n}=0
\end{gathered}
$$

Let us assume that the initial estimates of the $n$ variables are $\boldsymbol{x}_{1}{ }^{(\boldsymbol{\theta})}, \boldsymbol{x}_{2}{ }^{(\boldsymbol{\theta})}, \ldots, \boldsymbol{x}_{\boldsymbol{n}}{ }^{(\boldsymbol{\theta})}$. Let us add corrections $\Delta \boldsymbol{x}_{\boldsymbol{1}}{ }^{(\boldsymbol{\theta})}, \Delta \boldsymbol{x}_{2}{ }^{(\boldsymbol{\theta})}, \ldots, \boldsymbol{\Delta} \boldsymbol{x}_{\boldsymbol{n}}{ }^{(\boldsymbol{\theta})}$ to these variables such that the correct solution of these variables defined by

$$
\begin{gathered}
x_{1}^{*}=x_{1}^{(0)}+\Delta x_{1}{ }^{(0)} \\
x_{2}^{*}=x_{2}{ }^{(0)}+\Delta x_{2}{ }^{(0)} \\
\vdots \\
x_{n}^{*}=x_{n}^{(0)}+\Delta x_{n}{ }^{(0)}
\end{gathered}
$$
The functions in (3.1)
\[ g_{k}\left(x_{1}^{*}, \cdots, x_{n}^{+}\right)=g_{k}\left(x_{1}^{(0)}, \cdots\left(x^{(0)}\right)+\left.\Delta x_{1}^{(0)} \frac{\partial g_{k}}{\partial{ }^{(0)}}\right|_{k} ^{(0)}+\left.\Delta x_{20)}^{(0)} \frac{\partial g_{k}}{\partial x_{0}}\right|_{\text {, where } k=1, \ldots, x_{n}} ^{(0)}+\cdots+\left.\Delta x_{n}^{(0)} \frac{\partial g_{k}}{\partial x_{n}}\right|^{(0)} \text { then can be }\right. \]
written in
the variables terms of given in (3.3) as

$$
\partial g_{k} /\left.\partial x_{i}\right|^{(0)}
$$

Expand the above equation in Taylor's series around the nominal values of $\boldsymbol{x}_{\boldsymbol{1}}{ }^{(\boldsymbol{\theta})}, \boldsymbol{x}_{2}{ }^{(\boldsymbol{\theta})}, \ldots$ , $\boldsymbol{x}_{\boldsymbol{n}}{ }^{(\boldsymbol{\theta})}$. Neglecting the second and higher order terms of the series, the expansion of $\boldsymbol{g}_{\boldsymbol{k}}, \boldsymbol{k}=1, \ldots$ , $\boldsymbol{n}$ is given as

Where is the partial derivative of $g_{k}$ evaluated at $\boldsymbol{x}_{2}{ }^{(1)}, \ldots, \boldsymbol{x}_{\boldsymbol{n}}{ }^{(1)}$. Equation (3.5) can be written in vector-matrix form as

$$
\left[\begin{array}{cccc}
\partial g_{1} / \partial x_{1} & \partial g_{1} / \partial x_{2} & \cdots & \partial g_{1} / \partial x_{n} \\
\partial g_{2} / \partial x_{1} & \partial g_{2} / \partial x_{2} & \cdots & \partial g_{2} / \partial x_{n} \\
\vdots & \vdots & \ddots & \vdots \\
\partial g_{n} / \partial x_{1} & \partial g_{n} / \partial x_{2} & \cdots & \partial g_{n} / \partial x_{n}
\end{array}\right]^{(0)}\left[\begin{array}{c}
\Delta x_{1}{ }^{(0)} \\
\Delta x_{2}{ }^{(0)} \\
\vdots \\
\Delta x_{n}{ }^{(0)}
\end{array}\right]=\left[\begin{array}{c}
0-g_{1}\left(x_{1}{ }^{(0)}, \cdots, x_{n}{ }^{(0)}\right) \\
0-g_{2}\left(x_{1}{ }^{(0)}, \cdots, x_{n}{ }^{(0)}\right) \\
\vdots \\
0-g_{n}\left(x_{1}{ }^{(0)}, \cdots, x_{n}{ }^{(0)}\right)
\end{array}\right]
$$


The square matrix of partial derivatives is called the Jacobian matrix $\boldsymbol{J}$ with $\boldsymbol{J}^{(\boldsymbol{1})}$ indicating that the matrix is evaluated for the initial values of $\boldsymbol{x}_{2}{ }^{(\boldsymbol{\theta})}, \ldots, \boldsymbol{x}_{\boldsymbol{n}}{ }^{(\boldsymbol{\theta})}$. Then write the solution of (3.6) as

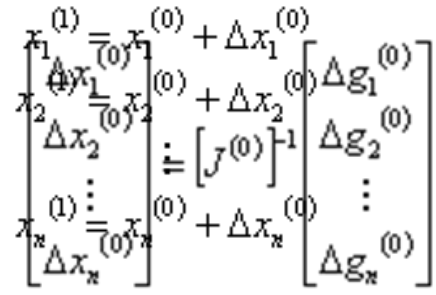

$$
\begin{aligned}
& \Delta g_{k}^{(0)}=g_{k}\left(x_{1}^{*}, \cdots, x_{n}^{+}\right)-g_{k}\left(x_{1}^{(0)}, \cdots, x_{n}^{(0)}\right)
\end{aligned}
$$

Since the Taylor's series is truncated by neglecting the $2^{\text {nd }}$ and higher order terms, It cannot expect to find the correct solution at the end of first iteration. So that go for further iterations.

These are then used to find $J^{(1)}$ and $\Delta g_{k}{ }^{(1)}, k=1, \ldots, n$. Then find $\Delta x_{2}{ }^{(1)}, \ldots, \Delta x_{n}{ }^{(1)}$ from an equation like (3.7) and subsequently calculate $\boldsymbol{x}_{2}{ }^{(\boldsymbol{l})}, \ldots, \boldsymbol{x}_{\boldsymbol{n}}{ }^{(\boldsymbol{l})}$. The process continues till $\Delta \boldsymbol{g}_{\boldsymbol{k}}, \boldsymbol{k}=1, \ldots, \boldsymbol{n}$ becomes less than a small quantity.

\subsection{Algorithm}

Step 1: Assign the input values for $\mathrm{I}_{\mathrm{SC}}, \mathrm{V}_{\mathrm{OC}}, \mathrm{V}_{\mathrm{MPP}}, \mathrm{I}_{\mathrm{MPP}} \& \mathrm{~N}_{\mathrm{S}}$.

Step 2: Initialize iter $=1, \mathrm{Vt}(\mathrm{old})=0 \&$ Calculate $\mathrm{Rsh}(\mathrm{old})$, Rse(old) For initialization.

Step 3: The condition Iter $=$ maxiter satisfies go fot next step if not stop.

Step 4: Evaluate values Vt(new), Rsh(new), Rse(new) \& A.

Step 5: Calculate error values $1 * \mathrm{e}-10$.

Step 6: The old values are updated Vt(old) $=\mathrm{Vt}($ new $), \operatorname{Rsh}($ old $)=\operatorname{Rsh}($ new $)$,

$\operatorname{Rse}($ old $)=\operatorname{Rse}($ new $)$.

Step 7: It cannot expect to find the correct solution at the end of first iteration.

So that go for further iterations Iter $=$ Iter+1.

Step 8: The end of iterations final values are updated as follows $\mathrm{Vt}($ final $)=\mathrm{Vt}(\mathrm{new})$, $\operatorname{Rsh}($ final $)=\operatorname{Rsh}($ new $) \& \operatorname{Rse}($ final $)=\operatorname{Rse}($ new $)$. 
Step 9: Evaluate Ilg,Isat \& A and stop the program.

The N-R method for estimate five parameters of PV module with help of equations (12),(13) \& (14) in STCs. The flowchart for evaluation of the five parameters of the PV module is shown in Figure 2.

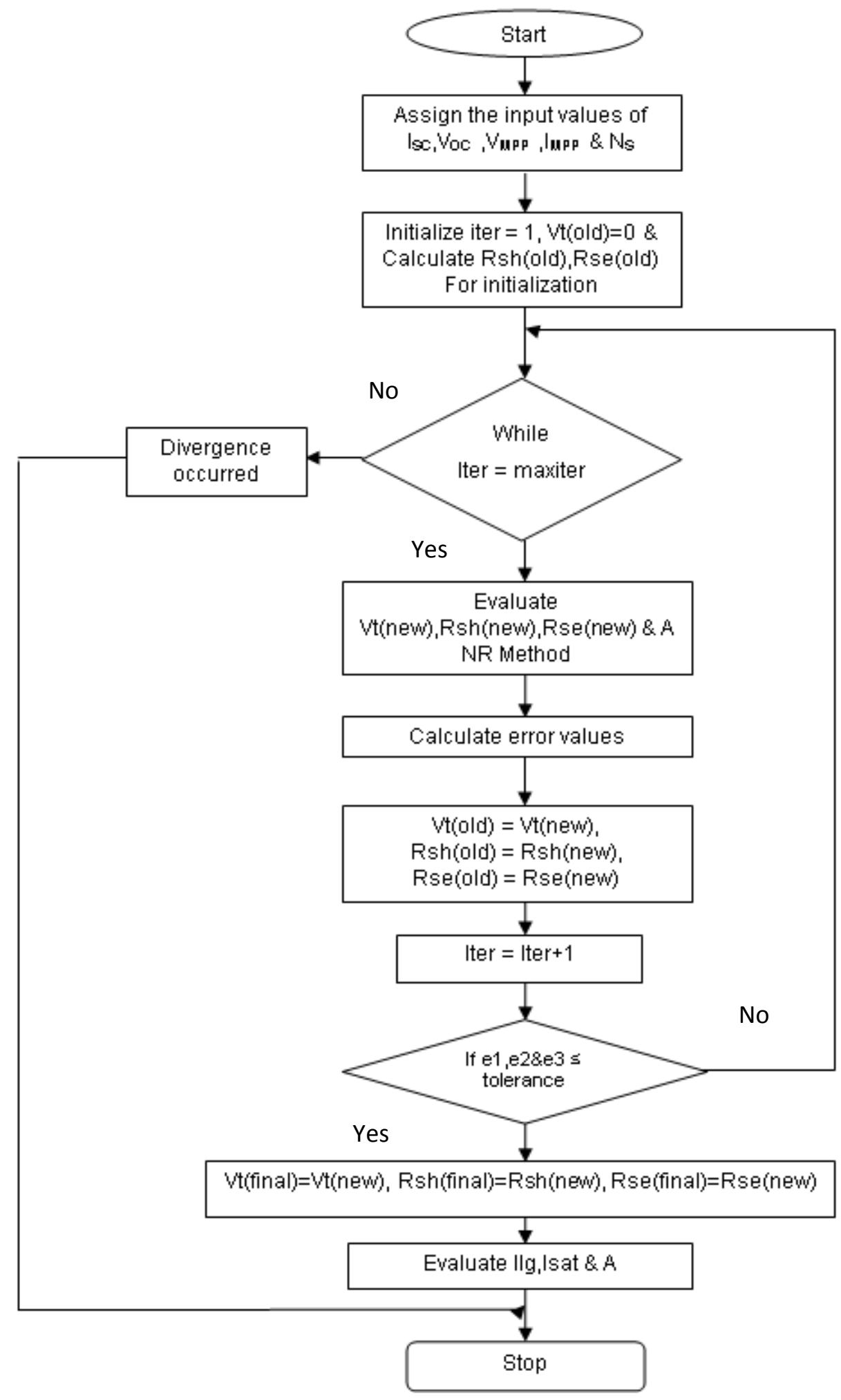


These values are given at STCs, for which the irradiance (Gstc) is $1000 \mathrm{~W} / \mathrm{m}^{2}$ and the cell temperature (Tstc) is $25 \circ \mathrm{C}$

Table 1. Datasheet of PV modules

\begin{tabular}{|l|l|l|l|l|l|}
\hline \multirow{2}{*}{ PV Module } & \multicolumn{5}{c|}{ Datasheet values } \\
\cline { 2 - 6 } & $\mathbf{I}_{\mathbf{s c}}(\mathbf{A})$ & $\mathbf{I}_{\mathbf{m p p}}(\mathbf{A})$ & $\mathbf{V}_{\text {oc }}(\mathbf{V})$ & $\mathbf{V}_{\mathbf{m p p}}(\mathbf{V})$ & $\mathbf{N}_{\mathbf{s}}$ \\
\hline KD245GX & 8.91 & 8.23 & 36.9 & 29.80 & 60 \\
\hline U5-80 & 5.21 & 4.58 & 21.34 & 17.46 & 36 \\
\hline Shell SP70 & 4.7 & 4.25 & 21.4 & 16.5 & 36 \\
\hline HST60FXXXM & 8.82 & 8.39 & 37.9 & 31.03 & 60 \\
\hline HST36FXXXP & 4.65 & 4.30 & 21.5 & 17.5 & 36 \\
\hline HST60FXXXP & 8.80 & 8.27 & 37.6 & 30.23 & 60 \\
\hline
\end{tabular}

Table 2. Estimated parameters for various PV modules at STCs

\begin{tabular}{|l|l|l|l|l|l|}
\hline \multirow{2}{*}{ PV Module } & \multicolumn{5}{|c|}{ Estimated parameters } \\
\cline { 2 - 6 } & $\mathbf{A}$ & $\mathbf{R}_{\text {se }}(\mathbf{\Omega})$ & $\mathbf{R}_{\mathbf{s h}}(\mathbf{\Omega})$ & $\mathbf{I}_{\mathbf{g}}(\mathbf{A})$ & Isat (A) \\
\hline KD245GX & 1.4290 & 0.1562 & 623.2350 & 8.9122 & $4.6709 \mathrm{e}-07$ \\
\hline U5-80 & 1.6043 & 0.0086 & 66.6312 & 5.2107 & $2.7593 \mathrm{e}-06$ \\
\hline Shell SP70 & 1.5536 & 0.3242 & 321.2234 & 4.2543 & $1.4181 \mathrm{e}-06$ \\
\hline HST60FXXXM & 0.9485 & 0.2920 & 38772.16 & 8.8201 & $4.8301 \mathrm{e}-11$ \\
\hline HST36FXXXP & 1.3862 & 0.1385 & 671.3679 & 4.6510 & $2.3925 \mathrm{e}-07$ \\
\hline HST60FXXXP & 1.1452 & 0.2893 & 4956.62 & 8.8005 & $4.9002 \mathrm{e}-09$ \\
\hline
\end{tabular}

The parameters are estimated in standard test conditions (STCs) and tabulated different PV modules of 250W solar panel KD245GX, HST60FXXXM, HST60FXXXP and 80W solar panels of U5-80, Shell SP70, HST36FXXXP.

The $\mathrm{N}-\mathrm{R}$ method for estimated five parameters of PV modules with help of equations (12),(13) \& (13) in STCs are shown in Table 2.

Table 3. Estimated parameters for various PV modules at varying irradiance and temperature

\begin{tabular}{|c|c|c|c|c|c|c|c|c|c|c|}
\hline 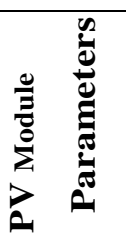 & $\begin{array}{l}\mathbf{G} \\
\left(\mathbf{W} / \mathbf{m}^{2}\right)\end{array}$ & $\begin{array}{l}\text { Tc } \\
\left({ }^{\circ} \mathbf{C}\right)\end{array}$ & A & $\begin{array}{l}\text { Rse } \\
(\Omega)\end{array}$ & $\begin{array}{l}\text { Rsh } \\
(\Omega)\end{array}$ & ILG (A) & $\begin{array}{l}\text { Isat } \\
\text { (A) }\end{array}$ & Vmpp (V) & Impp (A) & Pmpp (W) \\
\hline \multirow{3}{*}{ ลี } & 1000 & 30 & 1.48346 & 0.1562 & 623.2831 & 8.9122 & $6.16 \mathrm{E}-07$ & 29.8017 & 8.2304 & 245.3275 \\
\hline & 1000 & 50 & 1.39161 & 0.1562 & 623.2756 & 8.9123 & $1.71 \mathrm{E}-06$ & 29.799 & 8.2304 & 245.2597 \\
\hline & 1000 & 70 & 1.31046 & 0.1562 & 623.2682 & 8.9124 & $4.22 \mathrm{E}-06$ & 29.7962 & 8.2304 & 245.2404 \\
\hline
\end{tabular}




\begin{tabular}{|c|c|c|c|c|c|c|c|c|c|c|}
\hline & 1100 & 25 & 1.50013 & 0.1718 & 566.6227 & 9.8034 & $4.24 \mathrm{E}-07$ & 29.7861 & 9.0506 & 269.5705 \\
\cline { 2 - 10 } & 800 & 25 & 1.52890 & 0.125 & 779.1062 & 7.1298 & $5.85 \mathrm{E}-07$ & 29.6937 & 6.5839 & 195.4961 \\
\cline { 2 - 10 } & 600 & 25 & 1.4485 & 0.0937 & 1039 & 5.3465 & $5.833 \mathrm{e}-07$ & 29.3463 & 4.9321 & 145.2552 \\
\hline
\end{tabular}

\begin{tabular}{|c|c|c|c|c|c|c|c|c|c|c|}
\hline \multirow{5}{*}{ 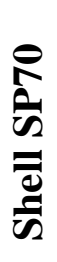 } & 1000 & 25 & 1.63987 & 0.3242 & 321.2234 & 4.7047 & $1.57 \mathrm{E}-06$ & 16.4999 & 4.2499 & 70.1221 \\
\hline & 800 & 25 & 1.66453 & 0.2594 & 401.5293 & 3.7638 & $1.97 \mathrm{E}-06$ & 16.5844 & 3.4061 & 56.4933 \\
\hline & 600 & 25 & 1.69741 & 0.1945 & 535.3723 & 2.8228 & $2.64 \mathrm{E}-06$ & 16.4795 & 2.5542 & 42.1024 \\
\hline & 400 & 25 & 1.75084 & 0.1297 & 803.0585 & 1.8819 & $4.01 \mathrm{E}-06$ & 16.0991 & 1.698 & 27.3323 \\
\hline & 200 & 25 & 1.84537 & 0.0648 & $1.61 \mathrm{E}+03$ & 0.9409 & $8.27 \mathrm{E}-06$ & 15.1711 & 0.8416 & 12.7678 \\
\hline \multirow{3}{*}{$\begin{array}{l}\mathscr{\infty} \\
\text { ஸ́ } \\
\text { ம் }\end{array}$} & 351 & 35.7 & 1.67421 & 0.003 & 189.3658 & 1.8335 & $1.41 \mathrm{E}-05$ & 15.7182 & 1.5949 & 25.0731 \\
\hline & 426 & 42 & 1.62451 & 0.0037 & 155.8012 & 2.2284 & $1.48 \mathrm{E}-05$ & 16.0523 & 1.9431 & 31.1902 \\
\hline & 568 & 44 & 1.57765 & 0.0049 & 116.7973 & 2.9726 & $1.18 \mathrm{E}-05$ & 16.5378 & 2.6 & 42.9893 \\
\hline \multirow{7}{*}{$\begin{array}{l}8 \\
0 \\
0 \\
0 \\
0 \\
0 \\
0 \\
0 \\
0 \\
0\end{array}$} & 841 & 49 & 1.4775 & 0.2802 & $6.87 \mathrm{E}+04$ & 8.2418 & 4.77E-05 & 22.1535 & 7.3418 & 162.6971 \\
\hline & 868 & 49 & 1.4775 & 0.2892 & $6.66 \mathrm{E}+04$ & 8.5064 & 4.84E-05 & 22.0907 & 7.5706 & 167.2258 \\
\hline & 872 & 49 & 1.4775 & 0.2905 & $6.63 \mathrm{E}+04$ & 8.5456 & $4.85 \mathrm{E}-05$ & 22.081 & 7.6044 & 167.8917 \\
\hline & 881 & 49 & 1.4775 & 0.2935 & $6.56 \mathrm{E}+04$ & 8.6338 & $4.87 \mathrm{E}-05$ & 22.0589 & 7.6804 & 169.3776 \\
\hline & 882 & 49 & 1.4775 & 0.2938 & $6.55 \mathrm{E}+04$ & 8.6436 & $4.87 \mathrm{E}-05$ & 22.0564 & 7.6889 & 169.5447 \\
\hline & 887 & 49 & 1.4739 & 0.2955 & $6.51 \mathrm{E}+04$ & 8.6926 & 4.74E-05 & 22.0439 & 7.731 & 170.4773 \\
\hline & 908 & 47.7 & 1.4559 & 0.3005 & $6.41 \mathrm{E}+04$ & 8.8394 & $3.49 \mathrm{E}-05$ & 22.3972 & 7.8853 & 176.5793 \\
\hline \multirow{5}{*}{$\sum_{\infty}^{\infty}$} & 832 & 43.8 & 1.3809 & 0.1763 & $3.67 \mathrm{E}+03$ & 7.9543 & $8.63 \mathrm{E}-06$ & 24.3232 & 7.2374 & 176.0508 \\
\hline & 835 & 43.8 & 1.3809 & 0.1769 & $3.66 \mathrm{E}+03$ & 7.983 & 8.63E-06 & 24.3224 & 7.2633 & 176.6694 \\
\hline & 840 & 43.8 & 1.3809 & 0.178 & $3.63 \mathrm{E}+03$ & 8.0308 & 8.64E-06 & 24.3209 & 7.3066 & 177.6929 \\
\hline & 845 & 43.8 & 1.3809 & 0.1791 & $3.61 \mathrm{E}+03$ & 8.0786 & $8.65 \mathrm{E}-06$ & 24.3192 & 7.3498 & 178.7144 \\
\hline & 849 & 43.8 & 1.3809 & 0.1799 & $3.59 \mathrm{E}+03$ & 8.1168 & $8.66 \mathrm{E}-06$ & 24.3177 & 7.3844 & 179.5342 \\
\hline
\end{tabular}

The light generated current and short circuit current are directly proportional to irradiance and also depend on temperature. The unknown parameters of PV module namely $\mathrm{I}_{\mathrm{lg}}, \mathrm{I}_{\mathrm{sat}}, \mathrm{A}, \mathrm{R}_{\mathrm{se}}$, and $\mathrm{R}_{\mathrm{sh} .}$, can be estimated at any temperature and irradiance condition.

PV modules of 250W solar panel KD245GX, HST60FXXXM, HST60FXXXP and 80W solar panels of U5-80, Shell SP70 are taken estimated parameters at any temperature and irradiance conditions are shown in Table 3.

\section{CONCLUSION}

In this work, the following PV modules are taken for estimate the five unknown parameters of KD245GX, U5-80, Shell SP70, HST60FXXXM, HST36FXXXP and HST60FXXXP. The N-R method is used to estimate the five unknown parameters of the PV modules at STCs. Here, good convergence is achieved in the N-R method during MATLAB coding, due to the selection of appropriate initial values from the series and shunt resistance equations. The SUR method is used to extract the MPP at different environmental conditions by considering the varying nature of shunt resistance, series resistance, and ideality factor. In particular, through the proposed equations of shunt resistance and ideality factor of the PV model, 

accurate MPP value is obtained. For a wide range of operating conditions, the MPP and the five unknown parameters of various PV modules are estimated.

\section{FUTURE SCOPE}

The proposed methodology estimate the five unknown parameters of the PV module at STCs and variable temperature and irradiance conditions. Five unknown parameters of the PV module can be obtained with the GHNN based optimization technique

Solar power from the PV module the converter will help to get maximum power by taking PV module references of voltage and current. Instead of taking reference from the PV module, for different environment conditions five parameters are determined and can be used for generating pulse signal for driving converter for deliver maximum power from PV module.

\section{REFERENCES}

[1] Rauschenbach HS, 1976, "Solar Cell Array Design Handbook", Vol. 1, JPL, Pasadena, CA, USA: Van Nostrand Reinhold.

[2] Celik AN, Acikgoz N, 2007, "Modelling and experimental verification of the operating current of mono-crystalline photovoltaic modules using four and five parameter models", Appl Energ; 84: $1-15$.

[3] Alonso-Garcia MC, Ruiz JM, 2006, "Analysis and modelling the reverse characteristic of photovoltaic cells", Sol Energ Mat Sol C; 90: 1105-1120.

[4] Carrero C, Ramirez D, Rodr' 1guez A, Platero CA, 2011, "Accurate and fast convergence method for parameter estimation of PV generators based on three main points of the I-V curve", Renew Energ; 36: 2972-2977.

[5] Zhu XG, Fu ZH, Long XM, Li X, 2011, "Sensitivity analysis and more accurate solution of photovoltaic solar cell parameters", Sol Energy; 85: 393-403.

[6] Saloux E, Teyssedou A, Sorin M, 2011, "Explicit model of photovoltaic panels to determine voltages and currents at the maximum power point", Sol Energy; 85: 713-722.

[7] Cotfas D, Cotfas P, Kaplanis S, Ursutiu D, 2008, "Results on series and shunt resistances in a c-Si PV cell, Comparison using existing methods and a new one", J Optoelectron Adv M ; 10: 3124-3130.

[8] Ly Diallo H, Dieng B, Ly I, Dione MM, Ndiaye M, Lemrabott OH, Bako ZN, Wereme A, Sissoko G, 2012, "Determination of the recombination and electrical parameters of a vertical multi junction silicon solar cell”, Res J Appl Sci Eng Technol; 4: 2626-2631. 
[9] Chatterjee A, Keyhani A, Kapoor D, 2011, "Identification of photovoltaic source models", IEEE T Energy Conver; 26: 883-889.

[10] Kulaksiz AA, 2013, "ANFIS-based estimation of PV module equivalent parameters: application to a stand-alone PV system with MPPT controller", Turk J Elec Eng \& Comp Sci 2013; 21: 2127-2140.

[11] De Soto W, Klein SA, Beckman WA, 2006, "Improvement and validation of a model for photovoltaic array performance", Sol Energy; 80: 78-88. 